LACOSTE, J.

PAGE, $G$.

QUINOT, B.

Hospital Militar de Instrucción

Mohamed V.

Rabat, Marruecos
M.I., M.G. En 124 tratamientos de diversas infecciones sólo se registraron dos fracasos. Gran eficacia del Bactrim en: Salmonelosis, Shigelosis, Meningitis purulenta, Infecciones urinarias, Infecciones broncopulmonares, Infecciones cutáneas. Excelente tolerancia.

\title{
L'ASSOCIATION SULFAMETHOXAZOLE-TRIMETHOPRIME EN PATHOLOGIE INFECTIEUSE
}

\author{
Thérapeutique, 47, 9: 853-55 (1971)
}

\section{Bactrim en patología infecciosa}

Lacoste y colaboradores hicieron un estudio detallado con Bactrim* Roche en 124 enfermos de diversas infecciones, cuya clasificación, posología adoptada y resultados, son como sigue:

49 salmonelosis. Se trataba en la mayoría de los casos de adultos jóvenes, de 20 a 31 años, y en 6, de niños de 10 a 14 años. Del total, 42 enfermos presentaban formas de mediana gravedad y 7 más severas. Se comenzó el tratamiento con Bactrim el décimo día de enfermedad, y en 10 casos al decimoquinto, administrando 4 comprimidos a los adultos y 2 comprimidos a los niños (peso promedio inferior a $35 \mathrm{~kg}$.). La duración del mismo fue en general de 14 días, o sea, en media, 8 días después de obtener la apirexia y se prolongó a 17-20 días sólo en 5 casos. Los resultados clínicos pueden clasificarse de excelentes y no hubo fracaso alguno. Buena tolerancia.

9 shigelosis. Por disentería bacilar fueron tratados 8 adultos y un niño de 10 años. En 5 casos se trataba de formas graves con más de 15 deposiciones diarias y repercusión sobre el estado general. El germen causante era Shigella Flexneri en 7 casos y Shigella Sonnei en los otros dos. Los adultos tomaron 4 comprimidos al día, dos cada doce horas, y la mitad el niño, durante 10 días. La evolución fue siempre rápidamente favorable. No se registró incidente alguno.

8 meningitis purulenta. En 7 casos se trataba de meningitis por meningococos y en l de meningitis purulenta post-otítica, cuyo germen no fue aislado. En 4 observaciones, se trató a los pacientes con Bactrim sólo a la dosis de 4 a 6 comprimidos diarios durante 15-20 días. En este grupo la mejoría fue sensible, quedando los enfermos apiréticos entre el $3^{\circ}$ y $8^{\circ}$ día.

En un caso, el Bactrim, a la dosis de 4 comprimidos diarios, en dos tomas, durante 15 días, fue asociado a 4.000.000 U. diarias de penicilina. La evolución fue rápidamente favorable. Hubo dos fracasos en que el germen

\footnotetext{
* Marca de Fábrica
} 
demostró resistencia in vitro al Bactrim. No se registró incidente alguno de tolerancia.

14 infecciones urinarias. Se trataba de infecciones graves en enfermos diabéticos, otros parapléjicos, algunos con pielonefritis y uno con orquiepididimitis. Se aislaron los siguientes gérmenes: Escherichia coli, Klebsiella, Proteus mirabilis, Pseudomonas aeruginosa. La mayoría de estos pacientes fueron tratados con dosis de 4 comprimidos -algunos 6 comprimidosal día durante un promedio de 12 días. En todos ellos los resultados clínicos y bacteriológicos fueron excelentes y no se observaron reacciones secundarias.

34 infecciones broncopulmonares. Clínicamente manifestadas como pneumopatías agudas, neumonía lobar por pneumococos, sobreinfección bronquial en bronquíticos crónicos, asmáticos, portadores de bronquiectasias o de abscesos del pulmón. Se trató a todos los pacientes, salvo a tres de pneumopatía, con sólo Bactrim; pero a estos tres últimos hubo que añadir penicilina por la gravedad de los síntomas iniciales. La dosis de Bactrim fue de 4 comprimidos diarias durante una media de 10 días. En el absceso pulmonar se administró una dosis diaria de 6 comprimidos la primera quincena, seguida de 4 comprimidos diarios hasta 35 días. En todos los casos la evolución fue satisfactoria. En uno sólo se presentó eosinofilia al cabo de 15 días de tratamiento, la cual desapareció rápidamente.

6 infecciones cutáneas. Tres de estos enfermos presentaban una piodermitis severa y otro una sicosis sobreinfectada, las que desaparecieron con la dosis corriente de Bactrim, en 10 a 15 días.

6 diversos. Se trataron con Bactrim, obteniendo resultados muy satisfactorios: una pústula carbuncosa (4 comprimidos durante 15 días), una leptospirosis íctero-hemorrágica (4 comprimidos durante 18 días) y 4 uretritis gonocócicas, de las cuales dos con orquiepididimitis. Los autores hacen referencia a otros trabajos en que se empleó una dosis única de 8 comprimidos de Bactrim.

Lacoste y colaboradores señalan en conclusión de este trabajo la grandísima eficacia del Bactrim y su excelente tolerancia. En las 124 observaciones sólo registraron 2 fracasos. No se presentaron trastornos gastrointestinales ni reacciones cutáneas. En el cuadro hematológico hubo que anotar dos casos transitorios de eosinofilia y dos de neutropenia, rápidamente regresivos. 